For determined suicidal attempts it was used in the case of two women. The one was continually attempting to compress her throat, and succeeded in thus producing hoarseness and ecchymosis of the conjunctiva; the other constantly tried to hammer her head and face on the floor or walls, and to tear out her eyes. The vigilance of attendants, however constant and well directed, is not sufficient to ensure the patient's safety in cases like these. This was lamentably demonstrated in a similar case which occurred elsewhere, where the patient, in spite of the continual care by night and day of two attendants, gouged out both his ejes.

For wholesale destruction of bedding, restraint was used in three cases, one male general paralytic, and two female imbeciles. The man was, perhaps, the most destructive patient I have ever seen; every kind of fabric was torn to pieces and every kind of bedding destroyed with a persistency and completeness almost incredible. When the ordinary means, occupation, amusement, vigilance, and sedatives all fail in such cases-and I know that they all do fail sometimes-what is to be done? Must the patient be allowed night after night, without the smallest benefit to himself, to destroy valuable property, and is the nightly collection of rags a thing to be proud of ? I make such a patient wear gloves at night, which in no way interfere with his movements, which greatly limit and of ten correct his destructive habits, and which give a chance of sleep when otherwise there would be none. Is there anything heinous in this if looked at in the light of common sense, and apart from a blind reverence for the mere name of nonrestraint?

Similar extreme views are sometimes held as to seclusion, but, as with restraint, the good of the individual patient should be the rule and limit of its use. Here it is used very rarely, only in six cases last year, but I am certain that where the violence is so great as to render personal control indispensable, it is wiser to leave the patient in his room for a time than to expose him to the irritation, excitement, and risk of being held by attendants, however numerous or experienced.

The indiscriminate use of restraint or seclusion cannot be too strongly condemned, but to abjure them under all circumstances is only another illustration of the proverb that the extreme of right is wrong. The undue use of "chemical restraint," or other means of repression, would be an evil substitute for their occasional use; and to demand from attendants vigilance that shall never flag, and patience that shall never tire, is to expect more than man can render.

In conclusion, I may say that these views are not at all singular, as you seem to think; they are held by many of our best asylum superintendents, and, apologising for the lergth of my letter, I thank you for the opportunity of thus expressing them.

I am, Sir, your obedient servant,

May, 1872.

D. YeLlowleEs, M.D., Medical Superintendent.

** Our correspondent's letter seems to show a sad want of appreciation of the fundamental principle of the nonrestraint system. The infliction of mechanical restraint demoralises those who use it and those who suffer it; giving rise, in the long run, to negligence and brutality in the former, and to dirty habits, noise, and excitement in the latter. We are quite sure that Dr. Conolly, were he living, would earnestly repudiate the interpretation which Dr. Yellowlees puts upon the revolution which he effected, and that he would see in Dr. Yellowlees's practice a confirmation of his worst fears, that the old system, with all its horrors, would, after a time, be brought back gradually. Dr. Yellowlees may act with discretion and judgment, but the argument which he employs would support the use of every possible form of mechanical restraint on the part of those who, to save trouble or expense, might choose to think it necessary. If our best asylum superintendents really endorse Dr. Yellowlees's views we shall be surprised; we had thought that there was scarcely an English county asylum in which there was a single instrument of mechanical restraint.-ED. $\mathrm{L}$.

\section{ANOTHER TATTOOED MAN.}

To the Editor of THE LANCET.

Sir,-In The LANCET of February 3rd there is an account of the tattroed man of Vienna. In the year 1861, when at Rivière du Loup, Canada, I had the fortune to meet with much such another person. This man's name was Chambers; he had been lieutenant and adjutant of the 49th Regt. (he showed me his commission). I was two days at the same hotel with him, during which time he kindly stripped himself for my inspection. He was a tall thin man, about fifty-two years old; grey hair; the whole of right side of face covered with strawberry stain. Commencing with a collar round the neck, and terminating at the wrists and middle of calf of legs with a most elaborate piece of embroidery, the whole of the body inclusive was one mass of tattooing. The main figures consisted of Birmhese gods and goddesses, the intermediate spaces filled in with Birmhese inscriptions, birds, beasts, fishes, and scrolls. There was not the space of a pin's-point left uncoloured, which was in red, black, and blue. Mr. Chambers' account of the matter is simply the following:- That when stationed with his regiment in Birmah ( $I$ have forgotten the year he said) many years ago, he, for the curiosity of the thing, had himself tattooed in this manner; the amount he paid the man who ornamented him was $\$ 40$ sterling. He also said that it was a very common thing amongst the natives, and Europeans frequently commenced the beautification but generally got tired of the pain before the affair was finished.

When at Quebec, last year, I asked if he was still alive, but was informed that he had died. This poor man had for many years earned a living by travelling the world over, blowing a penny whistle, and playing the concertina, which be did in a wonderful manner. He was not in the babit of exhibiting his tattooing, and it was only my being a military medical officer, and talking to him, that made him show himself to me; he seemed rather ashamed of his youthful freak. May not the Vienna man in all probability have been tattooed also in Birmah?

I am, Sir, yours, \&c.,
Brockville, Ontario.
G. E. Gascoigne, M.D., late R.A.

\section{THE WOROESTER INFIRMARY.}

\section{To the Editor of THE LANCET.}

SIR,-Your impression of Saturday last (4th instant) con . tains an article reflecting upon the Worcester Infirmary and its honorary staff, professedly founded upon an anonyynous letter in a local newspaper. As the article in question contains several errors, both as to facts and as to the inferences you have drawn from them, we trust you will do us the justice of inserting this correction in your next issue.

It is stated, in the first place, that there are but two physicians to the infirmary, that the committee have not filled up vacancies as they occur, and that this state of things is "detrimental both to the profession and to the public." Now, with reference to the latter clause, the simple facts are these:- The Worcester Infirmary contains 100 beds. The proportion of these usually occupied by medical and surgical cases respectively is 40 to 60 ; the actual number of cases under the care of the physicians ranging between 25 and 35. The out-patients are under the care of, and are regularly seen twice a week by, the members of the staff themselves.

Until the last few weeks the number of physicians and surgeons on the staff was three of each. Statistics will inform you that this is a larger proportional number than is enjoyed, with one exception, by any other hospital of the same size in the kingdom. The average number of physicians to 100 beds is something less than two, of surgeons less than three; whilst in larger hospitals the proportion of the staff to beds is still less. So much for any detriment to the interests of the public. In the interest of the profession, it is implied that there are, or may be, two physicians in Worcester who are excluded from the advantages of the practice of the infirmary. The facts again are these:There are two, and only two, graduates in medicine in this city who do not hold office in the infirmary. One of these declines to become a candidate for the single vacancy that 
has just occurred; and the application of the other was not entertained by the committee. "Hinc illa lachryme" of your possible correspondent. Then, as regards the rule of the infirmary, by which its physicians are restricted from general practice, whatever differences of opinion may prevail upon this subject, it bas, at all events, the full concurrence of the Executive Committee, and, it is believed, of the whole medical profession of the city and county.

Turning now to the surgical side, the first allegation is that the practitioners in Worcester are not even invited to witness the operations performed in the infirmary. Our answer to this is that, out of thirteen medical men practising in this city unconnected with the infirmary, all, with the exception of two, have been frequently present by invitation at the operations; and whenever there have been cases of unusual interest, such as ovariotomy, \&c., members of the profession in the county have also been invited. Then, as to the second allegation, that the general body of practitioners in the city and county are not free to witness the operations, we beg to draw your attention to the following rule: "Gentlemen of the profession in the city of Worcester and neighbourhood may be admitted by the honorary surgeons to witness the operations at the infirmary, with the concurrence of the operating surgeon." This surely affords every facility for witnessing the opera. tions by all our medical brethren, especially as there is a fixed day and hour for the purpose; and it has always given us pleasure to see them present.

We trust that you will now see that there is no "mystery or secrecy" in the surgical management of the infirmary, and that we do not "conceal our lights beneath the bushel of exclusiveness and clique."

We are, Sir, your obedient servants,

William Strange, M.D. Senior Physician to the Infirmary.

May, 1872. Herbert W. Budd, Senior Surgeon.

\section{On behalf of the Staff.}

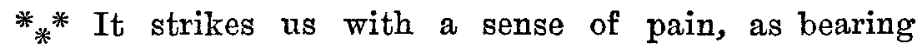
upon the status and habits of the Worcester staff, that our correspondents appear to be unaccustomed to hold communication with gentlemen. We stated plainly what our article was founded upon; and the inuendo contained in the words "professedly founded," and in the words "your possible correspondent," is an impertinence that we need not find an adjective to characterise. The substance of our correspondents' letter absolutely proves our case step by step, except in one particular. Dr. Strange and Mr. Budd assert that there were never more than three physicians. "Charity" asserted that there were originally four. Between the conflicting statements we must leave local antiquaries to decide. Our argument as to what ought to be is left wholly untouched; and no amount of mismanagement on the part of the Executive Committee, or of analogous mismanagement at other places, can convert wrong into right. "The Medical Directory" contains the names of seven graduates in medicine (two M.B.s and five M.D.s) as practising in Worcester. Three of these only, omitting Dr. Williams, are connected with the Infirmary, one as consulting, the others as acting physicians. There are, therefore, at least three gentlemen, and not two only, who might be eligible for office. As regards surgery, the letter proves our point still more completely. We stated or implied that medical practitioners, as such, ought to feel themselves at full liberty to go and witness operations without invitation; that the hospital was a public institution in no way the property of its medical staff; and that its doors ought to stand open to the profession at all reasonable times. We are told in reply that out of thirteen practitioners (why thirteen, when there are twenty-seven in the "Directory?") all but two have been frequently present "by invitation" at the operations. We say that the eleven should have needed no invitation, and that the two should have needed it as little. We are referred to a rule which says that "gentlemen of the profession may be ads mitted by the honorary surgeons, with the concurrence of the operating surgeon"; and we say that the rule is preposterous, besides being radically vicious and unsound in principle. The honorary surgeons are representative men, discharging a trust, and the profession has a right to be admitted, not by them, or with their concurrence, but by the governors, to see how they discharge it. The fact is, that the old battle which THE LANCET fought forty years ago, in the case of London hospitals, has to be fought over again in provincial towns; and that the evils are there in many cases rampant, which in the metropolis the light of publicity has dispelled.-ED. L.

\section{THE RICHMOND IN FIRMARY.} To the Editor of ThE LANCET.

SIR,-When the Richmond Infirmary was established some few years ago, a somewhat peculiar rule was made, that no person should be eligible for the post of medical officer " until after three years' residence in the town." This, at that time, excluded myself and others. Last week a new appointment was created, that of "medical attendant to see out-patients at the infirmary." Amongst the candidates for that office were Dr. Fenn, who, within the last year, has become a partner in what formerly was, and possibly is now, one of the leading practices of the place, and myself. Finding the interest for this gentleman so great, doubtless through the great influence of his well. known predecessor and that of his present partner, I saw no other alternative but, at the last moment, to resign. What I would wish to ask is this, What chance has a man, striving by himself, of ever hoping to obtain an office in the Richmond Infirmary against a gentleman backed up at once by the great interest of an influential predecessor, and whose present partner is not only a governor of the infirmary-doubtless attending several, if not many of the governors, - but is also medical officer to in-patients? Secondly (and here lies the peculiarity of the case), the successful candidate has not been in Richmond one year. If a rule was made at the establishment of the infirmary that "no person shall be eligible until after three years' residence in the town," which at that time excluded myself and others, how comes it that Dr. Fenn, of all others, is elected upon the present occasion?

I beg to remain, Sir, your obedient servant, John WINNall George, M.R.C.S.

Richmond, Surrey, May 8th, 1872.

\section{THE DIAGNOSIS OF SMALL-POX.}

\section{To the Editor of THE LANCET.}

SIR,-Your remarks in last week's annotations on the necessity of medical men exercising great care in forming a correct diagnosis before consigning patients to a fever hospital, apply, especially at the present time, to cases of small-pox. Out of 180 of these lately sent to the hospital with which I am connected, 16 proved to be not small-pox at all. They were all of course carefully revaccinated as soon as the error was discovered, but, at periods varying from ten to fourteen days after admission, 4 developed the disease, and one of these died.

I am, Sir, your obedient servant,

May 13th, 1872. A Medicar. OfFicer.

\section{MANCHESTER}

\section{(FROM OUR OWN CORRESPONDENT.)}

Art the last meeting of the Manchester Medical Society, Dr. Leech showed a most instructive case of paralysis of the portio dura and the fifth nerves, occurring in a man under his care at the Chorlton Union Hospital. Mr. Whitehead showed a number of interesting cases in surgery, inclnding the following :-A woman, from whom he had remored the half of the lower jaw for fibro-plastic tumou'; a case in 